\title{
Survey Expectations and Learning ${ }^{1}$
}

\author{
Sergey Slobodyan, CERGE-EI \\ sergey.slobodyan@cerge-ei.cz \\ Raf Wouters, National Bank of Belgium; \\ Université Catholique de Louvain \\ rafael.wouters@nbb.be
}

\begin{abstract}
In this paper, we evaluate a model that describes real-time inflation data together with the inflation expectations measured by the Survey of Professional Forecasters (SPF). We work with a second-order autoregressive model in which the agents learn over time the intercept and persistence coefficients based on real-time data. To model the process of revisions in real time data, we allow for news and noise disturbances. In contrast to the usual time-varying parameter vector autoregression, we use non-linear Kalman filter techniques to estimate the time-varying coefficients of the underlying inflation process. We identify systematic changes in the persistence of the inflation process and in the long-run expected inflation rate that are implied by the model. The inflation forecasts implied by the model are then compared with the SPF forecasts. As we cannot reject the hypothesis that the SPF forecasts are produced based on our model, we re-estimate the model using Survey nowcasts and forecasts as additional observables. This augmented model does not change the nature and magnitude of the time variation in the coefficients of the autoregressive model, but it does help to reduce the uncertainty in the estimates. Overall, the estimated time-variation confirms our results on the perceived inflation process present in estimated DSGE models with learning (Slobodyan and Wouters, 2012a, 2012b).
\end{abstract}

Keywords: inflation expectations, learning, DSGE, TVP

JEL Codes: $C 11, C 52$,

D84, E30
Citation: Slobodyan, S. and Wouters, R. (2021). Survey Expectations and Learning. Russian Journal of Money and Finance, 80(2), pp. 3-27.

doi: $10.31477 /$ rjmf.202102.03

\footnotetext{
${ }^{1}$ The first author expresses sincere gratitude to National Bank of Belgium for the hospitality and support which made this project possible. This project was also supported by the Czech Science Foundation (GACR) grant P402-11-J018 'Comparative Approach to Macroeconomic Modelling and Policy Analysis: Introducing Adaptive Learning. The views expressed are solely our own and do not necessarily reflect those of the National Bank of Belgium.
} 


\section{Introduction}

In this paper, we analyse which types of forecasting models and learning dynamics are consistent with the inflation expectations measured by the Survey of Professional Forecasters (SPF). We start with a simple autoregressive model in which agents learn and update over time based on real-time data, and we allow for news and noise disturbances in the subsequent releases of the inflation data. We use non-linear Kalman filter techniques to estimate the time-varying coefficients of the underlying inflation process and identify systematic changes in the persistence of the inflation process and in the long-run expected inflation rate that are implied by these models. We evaluate the implied inflation forecasts and compare them with the SPF forecasts. As we cannot reject the hypothesis that the SPF forecasts are produced based on our model, we re-estimate the model using Survey nowcasts and forecasts as additional observables. In this way, we exploit the information from the surveys to discover the properties of the underlying forecasting model. This augmented model does not change the nature and magnitude of the time variation, but it does help to reduce the uncertainty in the estimates. Overall, the estimated time-variation confirms our results on the perceived inflation process present in estimated dynamic stochastic general equilibrium (DSGE) models with learning.

In Slobodyan and Wouters (2012b), we re-estimated the Smets and Wouters (2007) model under the assumption that agents formulate their expectations based on small forecasting models. Agents update the coefficients of these belief models over time by a simple Kalman filter procedure. This flexible updating process generates important time variation in the perceived inflation persistence and in the long-run inflation target. The learning model has important consequences for the propagation of exogenous shocks through the economy: expectations based on these under-parameterised models may amplify the propagation of shocks, especially during periods when the perceived inflation persistence is high. We observed that this endogenous propagation mechanism could be substituted for persistence in exogenous price-markup shocks. We also illustrated that the forecasts implied by the small time-varying forecasting models displayed a higher correlation with the SPF inflation expectations than the forecasts from the Rational-Expectations-DSGE (RE-DSGE) model.

The strong and robust results of learning dynamics in DSGE models confirmed the important role of expectations in the inflation process and called for the explicit modelling of the expectations mechanism in macro models. But at the same time, the evidence remained indirect, because no explicit observables on inflation expectations were used in the determination and estimation of the models for inflation expectations. This raises various questions. How realistic is the assumption that agents' expectations are based on small forecasting models that use only a limited information set? Are these forecasts dominated by the 
forecasts of larger models or by actually observed forecasts in the surveys because all the available information is not exploited efficiently? Why would agents' forecasting models not converge to the actual law of motion of the inflation process, which is more complex? These concerns about our previous study results motivated this paper. Using explicit evidence from the SPF on inflation expectations, we evaluate the forecasting performance of a simple time-varying autoregressive model. The forecast performance of our small models with timevarying parameters (TVP) is comparable to that of the SPF forecasts, and the forecast errors are highly correlated with those of the SPF. We illustrate that the time variation in the model parameters is robust both when estimated on inflation releases only and on inflation releases and survey forecasts together. These findings provide more direct evidence that support the hypothesis that small forecasting models and their implied time-variation provide a realistic representation of actual inflation expectations.

This paper extends the exercise of Branch and Evans (2006) in various ways. They evaluate the forecasting performance of alternative learning mechanisms for inflation and growth, and they conclude that simple models compare well with the SPF forecasts. In contrast, we perform the following. First, we take the real-time nature of the SPF forecasts into account more seriously by allowing for a general noise-news setup (following Jacobs and van Norden (2011), as suggested by Croushore (2011)). Second, we consider a non-linear Kalman filter approach for estimating the time variation in the parameters of the forecasting model. Third, we document the nature of the time variation in the forecasting model both in terms of implied inflation persistence and implied long-run inflation forecast. This time variation resembles the learning dynamics that we identified in the estimation of the DSGE model. Finally, after evaluating the forecasting model based on inflation releases only, we also re-estimate the model taking the SPF nowcasts and forecasts as additional observations to exploit the information from the SPF more intensively. The forecasting dynamics and time variation present in the survey forecasts confirm the learning dynamics of the model, using actual releases only.

This work is also related to a paper by Del Negro and Eusepi (2011). They also exploit SPF forecasts to test alternative hypotheses on the relevant expectation models. As in Slobodyan and Wouters (2012b), they indicate an important divergence between the implied expectations in RE-DSGE models and SPF evidence. They find strong evidence for time variation in the inflation objective as the underlying source of fluctuations in inflation expectations. Milani (2011), using SPF data combined with real-time data, also observes large deviations between model forecasts and SPF evidence, and he suggests that these expectation 'shocks' might be an important source of business cycle fluctuations. In contrast with these findings, our results suggest that simple time-varying models can produce forecasts that are very similar to the SPF data, and our augmented 
models, including the SPF forecasts, require minimal measurement errors to reproduce these survey forecasts.

The final objective of our research project is to integrate the survey data directly into the estimation of the overall DSGE model as additional observables. This integration is complicated by at least two practical issues. The first problem is related to the real-time data problem. When agents report their expectations in the SPF, they are observing only the first release of the realisation of inflation. As we use a GDP deflator in our model, these series deviate considerably from the final data series that are typically used in the estimation of DSGE models. The second problem is related to the timing of the survey and the available information set at that point. In a DSGE model, the timing is simple, as agents provide expectations for inflation for period $t+1$ based on the data available at time $t$. In the SPF, this is more complicated, as the survey takes place in the second month of each quarter and, at that point, agents have access to the first release for the previous quarter's inflation and make a nowcast for the current quarter and a forecast for the next quarter. The nowcast is, however, not exactly comparable to a standard forecast, as agents have already received some signal about the inflation process during the current quarter. On the other hand, the forecast for the next quarter is based on less information than is standard in the DSGE model. We consider this exercise a first exploration of the SPF data and leave the full integration of survey data into the DSGE model for future research.

\section{Forecasting model and data}

Here, we present our news-noise model assuming a second order autoregressive process $(\mathrm{AR}(2))$ for the underlying inflation process and considering two data releases. The model can easily be extended for higher order or moving average and for additional releases. First, a fixed coefficient model is presented. We explain how the model forecasts can be connected with the forecasts measured by the SPF, and we discuss the implications of the model for simple regressions of forecasts on lagged releases. Then we extend the model by allowing for time variation in the parameters. This results in a non-linear model, and the corresponding non-linear Kalman filter is derived. Finally, we show how survey evidence can be integrated into the estimation process, assuming that our model corresponds with the actual model used by the survey forecasters.

\subsection{News-noise set-up}

The model set-up is based on Jacobs and van Norden (2011). The basic objective of that paper is to model the measurement errors in real-time data and divide them into news and noise components. 
Definition 1: Denoting the 'true' value of a macroeconomic variable as $\tilde{y}_{t}$, and the estimate of $\tilde{y}_{t}$ of 'vintage' $t+i$, that is, published at $t+i$, as $y_{t}^{t+i}$, we say that the stochastic measurement error is pure noise if

$$
y_{t}^{t+i}=\tilde{y}_{t}+\varsigma_{t}^{t+i}, \quad \operatorname{cov}\left(\tilde{y}_{t}, \varsigma_{t}^{t+i}\right)=0
$$

Noise is uncorrelated with true value, but it may be correlated with data release $y_{t}^{t+i}$.

Definition 2: The measurement error is pure news if it behaves as a rational forecast error and is uncorrelated with the data release:

$$
y_{t}^{t+i}=\tilde{y}_{t}+v_{t}^{t+i}, \quad \operatorname{cov}\left(y_{t}^{t+j}, v_{t}^{t+i}\right)=0, \quad \forall j \leq i
$$

The assumptions make sure that, in the presence of a pure news shock, changes in the data from one release to another, $y_{t}^{t+i+1}-y_{t}^{t+i}$, must be unpredictable. On the other hand, in the presence of a pure noise shock, these changes might be predictable. Following Jacobs and van Norden (2011), we define the news shock $v_{t}^{t+i}$ further as

$$
v_{t}^{t+i}=-\sum_{j=i}^{h} \eta_{t}^{v j}
$$

where $h$ denotes the number of vintages that is used to estimate the model. It is implicitly assumed that for vintages above $h$ there are no further news signals, and the 'quasi-final' or 'no further news' release need not be included in the information set used for estimation.

\subsubsection{Fixed coefficient model}

In the general case where both news and noise are considered, the measurement equations for the two data releases published at time $t+1$ for inflation in periods $t$ and $t-1$ become, respectively:

$$
\begin{gathered}
y_{t}^{t+1}=\tilde{y}_{t}+v_{t}^{1}+\varsigma_{t}^{1}, \\
y_{t-1}^{t+1}=\tilde{y}_{t-1}+v_{t-1}^{2}+\varsigma_{t}^{2} .
\end{gathered}
$$

The corresponding transition equations for the AR(2) model can be written as a function of the fundamental shock $\left(\epsilon_{t}\right)$ and the news process

$$
\tilde{y}_{t}=\mu+\rho_{1} \tilde{y}_{t-1}+\rho_{2} \tilde{y}_{t-2}+\epsilon_{t}-v_{t}^{1}
$$

with the following set of exogenous processes and their white noise innovations $\eta_{t}$ :

$$
v_{t}^{1}=\eta_{t}^{\nu 1}+\eta_{t}^{v 2}, v_{t}^{2}=\eta_{t}^{\nu 2}, \varsigma_{t}^{1}=\eta_{t}^{{ }^{1}}, \varsigma_{t}^{2}=\eta_{t}^{\varsigma 2} \text { and } \epsilon_{t}=\eta_{t}^{\epsilon}
$$


This baseline model provides a very flexible set-up to model the two data releases with five stochastic disturbances. In principle, all five stochastic shocks can be identified, but we will test whether this flexible form is necessary by considering more restrictive models with only news or only noise disturbances. We consider this simple model as a potential description of the model that SPF participants use when forming their expectations. Under this assumption, we can also use SPF nowcasts and forecasts as observables in the model forecasts. The identification of shocks and parameters can be expected to be much more precise when we extend the list of observables with information from SPF forecasts. The model forecast for inflation at time $t+1$ corresponding with the SPF forecast for time $t+1$ (the zero-quarter-ahead forecast or nowcast) is the rational expectation given current data, and equals

$$
y_{t+1}^{t+1}=y_{t+1}^{n}=\mu+\rho_{1} \tilde{y}_{t}+\rho_{2} \tilde{y}_{t-1}+\varepsilon_{t}^{n}
$$

In the case of the forecast for time $t+2$, corresponding to the one-quarterahead forecast, the expression becomes

$$
y_{t+2}^{t+1}=y_{t+2}^{f 1}=\left(1+\rho_{1}\right) \mu+\left(\rho_{1}^{2}+\rho_{2}\right) \tilde{y}_{t}+\rho_{1} \rho_{2} \tilde{y}_{t-1}+\varepsilon_{t}^{f 1} \text {. }
$$

If the observed forecasts are in line with the model expectations, the additional measurement errors $\varepsilon_{t}^{n}$ and $\varepsilon_{t}^{f}$ should be minimal.

Plugging in the expressions for $\tilde{y}_{t}$ and $\tilde{y}_{t-1}$ from equation (1), we obtain:

$$
\begin{aligned}
y_{t+1}^{n}=\mu+ & \rho_{1}\left(y_{t}^{t+1}-v_{t}^{1}\right)+\rho_{2}\left(y_{t-1}^{t+1}-v_{t-1}^{2}\right)+\varepsilon_{t}^{n} \\
& =\mu+\rho_{1} y_{t}^{t+1}+\rho_{2} y_{t-1}^{t+1}+\rho_{1}\left(\eta_{t}^{\nu 1}+\eta_{t}^{\nu 2}\right)+\rho_{2}\left(\eta_{t-1}^{v 2}\right)+\varepsilon_{t}^{n} .
\end{aligned}
$$

This reduced form incorporates an iid shock, $\rho_{1} \eta_{t}^{v 1}$, and an MA-type shock, $\eta_{t}^{v 2}$; the MA coefficient is given by $\rho_{2} / \rho_{1}$. This feature of the model is important, as it is consistent with the results from ordinary least squares (OLS) regressions of $y_{t+1}^{n}$ on the two real-time data releases: these regressions typically generate a highly significant MA error term with a positive MA coefficient. Such an MA term is absent in OLS regressions of actual inflation releases on two lags, which is also consistent with our set-up. Including additional releases of past lags in the list of observables is not helpful for forecasting. These variables mainly allow the identification of past news shocks, but they do not contain any additional information related to other shocks, such as fundamental shocks or current news and noise shocks. In the pure news model, there is no confusion, as the equations of the model force the estimation procedure to attribute all the unexpected change in, say, the second release of time $t-1$ inflation to the shock $\eta_{t}^{v 2}$. 


\subsubsection{Time-varying parameter mode|}

In a TVP model, the constant term $\mu$ and the autocorrelation coefficients $\rho_{1}$ and $\rho_{2}$ become part of the state vector $\left[\tilde{y}_{t}, \tilde{y}_{t-1}, v_{t}^{1}, v_{t}^{2}, \mu_{t}, \rho_{t}^{1}, \rho_{t}^{2}\right]$, and the corresponding state transition equation becomes nonlinear.

$$
\begin{gathered}
{\left[\begin{array}{c}
\tilde{y}_{t} \\
\tilde{y}_{t-1} \\
v_{t}^{1} \\
v_{t}^{2} \\
v_{t-1}^{2} \\
\mu_{t} \\
\rho_{t}^{1} \\
\rho_{t}^{2}
\end{array}\right]=\left[\begin{array}{c}
\mu_{t-1} \\
0 \\
0 \\
0 \\
0 \\
\bar{\mu} \\
\bar{\rho}^{1} \\
\bar{\rho}^{2}
\end{array}\right]+\left[\begin{array}{cccccccc}
\rho_{t-1}^{1} & \rho_{t-1}^{2} & 0 & 0 & 0 & 0 & 0 & 0 \\
1 & 0 & 0 & 0 & 0 & 0 & 0 & 0 \\
0 & 0 & 0 & 0 & 0 & 0 & 0 & 0 \\
0 & 0 & 0 & 0 & 0 & 0 & 0 & 0 \\
0 & 0 & 0 & 1 & 0 & 0 & 0 & 0 \\
0 & 0 & 0 & 0 & 0 & \rho & 0 & 0 \\
0 & 0 & 0 & 0 & 0 & 0 & \rho & 0 \\
0 & 0 & 0 & 0 & 0 & 0 & 0 & \rho
\end{array}\right]\left[\begin{array}{c}
\tilde{y}_{t-1} \\
\tilde{y}_{t-2} \\
v_{t}^{1} \\
v_{t-1}^{2} \\
v_{t-2}^{2} \\
\mu_{t-1} \\
\rho_{t-1}^{1} \\
\rho_{t-2}^{2}
\end{array}\right]} \\
+\left[\begin{array}{cccccc}
1 & 1 & 1 & 0 & 0 & 0 \\
0 & 0 & 0 & 0 & 0 & 0 \\
0 & -1 & -1 & 0 & 0 & 0 \\
0 & 0 & -1 & 0 & 0 & 0 \\
0 & 0 & 0 & 0 & 0 & 0 \\
0 & 0 & 0 & 1 & 0 & 0 \\
0 & 0 & 0 & 0 & 1 & 0 \\
0 & 0 & 0 & 0 & 0 & 1
\end{array}\right]\left[\begin{array}{c}
\eta_{t}^{\epsilon} \\
\eta_{t}^{v 1} \\
\eta_{t}^{v 2} \\
\eta_{t}^{\mu} \\
\eta_{t}^{\rho 1} \\
\eta_{t}^{\rho 2}
\end{array}\right]
\end{gathered}
$$

The measurement equation is written as a non-linear function of the time $t$ state vector.

$$
\begin{aligned}
{\left[\begin{array}{c}
y_{t}^{t+1} \\
y_{t-1}^{t+1} \\
y_{t+1}^{n} \\
y_{t+2}^{f 1}
\end{array}\right] } & =\left[\begin{array}{c}
0 \\
0 \\
\mu_{t} \\
\left(1+\rho_{t}^{1}\right) \mu_{t}
\end{array}\right] \\
+ & {\left[\begin{array}{cccccccc}
1 & 0 & 1 & 0 & 0 & 0 & 0 & 0 \\
0 & 1 & 0 & 0 & 1 & 0 & 0 & 0 \\
\rho_{t}^{1} & \rho_{t}^{2} & 0 & 0 & 0 & 0 & 0 & 0 \\
\left(\rho_{t}^{1}\right)^{2}+\rho_{t}^{2} & \rho_{t}^{1} \rho_{t}^{2} & 0 & 0 & 0 & 0 & 0 & 0
\end{array}\right]\left[\begin{array}{c}
\tilde{y}_{t} \\
\tilde{y}_{t-1} \\
v_{t}^{1} \\
v_{t}^{2} \\
v_{t-1}^{2} \\
\mu_{t} \\
\rho_{t}^{1} \\
\rho_{t}^{2}
\end{array}\right]+\left[\begin{array}{c}
S_{t}^{1} \\
S_{t}^{2} \\
\varepsilon_{t}^{n} \\
\varepsilon_{t}^{f}
\end{array}\right] }
\end{aligned}
$$

For the baseline model, only the first two releases are used as observables. In the augmented models, the nowcasts and forecasts are included as well, and this introduces some additional non-linearity to the model. We rely on the extended Kalman filter to estimate this TVP model. 
We interpret our approach as a one-step filtering problem that agents are solving in real time to estimate simultaneously the true underlying inflation rate and the best forecasting model for future inflation expectations. This one-step approach differs from the usual practice in the learning literature. This tradition separates the learning step, the estimation of the perceived law of motion, and the estimation of actual decisions and policy rules. In our context, this separation is not very natural, as it implies that agents first solve a filtering problem in order to find out the underlying inflation data, and then, in a subsequent step, they use these filtered inflation data to estimate their forecasting models. This implies that agents are not using actual inflation data when formulating expectations, but only filtered data. Furthermore, the problem of estimating the true underlying inflation rate, which can imply corrections for news and noise disturbances in the first release data, is directly related to the dynamic properties of the underlying inflation process and, therefore, the more consistent approach is to treat this issue as a one-step filtering problem.

\subsection{Data and timing conventions}

The data on inflation releases are derived from the Real-Time Data Set for Macroeconomists available on the Philadelphia Fed website. ${ }^{2}$ We concentrate on the inflation measured by the GDP deflator. The forecasts are taken from the Survey of Professional Forecasters available on the same website. We use the median forecast series. The estimation period runs from 1971Q3 to 2009Q3. We consider typically two subperiods running from 1971Q3 to 1983Q4 and from 1984Q1 to 2009Q3.

A word on notation: In the above set-up, we explicitly take into account the date at which observables become known. At time $t+1$, we can observe the first release for time $t$ inflation, the second release for $t-1$ inflation, the zero-quarterahead SPF forecast or nowcast for $t+1$ inflation, the one-quarter-ahead SPF forecast for $t+2$ inflation, and so on.

\section{Estimation results and evaluation of forecast performance}

\subsection{Basic features of the data}

Table 1 documents the means and standard deviations for actual data releases and revisions on inflation and for SPF forecasts and reports on the root mean square error (RMSE), and the biases in these forecasts (zero- and one-quarterahead forecast). Statistics are shown for the complete observation period and the two subsamples.

\footnotetext{
${ }^{2}$ See https://www.philadelphiafed.org/surveys-and-data/real-time-data-research/ real-time-data-set-for-macroeconomists
} 
The table illustrates:

- The relatively low volatility of the forecasts compared to the actual data releases;

- The size of the revisions from first to second releases on inflation;

- The presence of substantial bias in SPF nowcasts and forecasts, at least during the subsamples;

- The quality of the SPF forecasts in terms of RMSE as a reference point for the model forecasts.

Table 1. Basic statistics in real-time data and SPF forecasts

\begin{tabular}{|c|c|c|c|c|c|c|c|c|c|c|}
\hline & \multicolumn{2}{|c|}{ First release } & \multicolumn{2}{|c|}{ First revision } & \multicolumn{3}{|c|}{$\begin{array}{l}\text { Forecast zero-quarter- } \\
\text { ahead }\end{array}$} & \multicolumn{3}{|c|}{$\begin{array}{l}\text { Forecast one-quarter- } \\
\text { ahead }\end{array}$} \\
\hline & Mean & $\begin{array}{l}\text { Standard } \\
\text { deviation }\end{array}$ & Mean & $\begin{array}{l}\text { Standard } \\
\text { deviation }\end{array}$ & Bias & $\begin{array}{l}\text { Standard } \\
\text { deviation }\end{array}$ & RMSE & Bias & $\begin{array}{l}\text { Standard } \\
\text { deviation }\end{array}$ & RMSE \\
\hline $\begin{array}{l}\text { Complete } \\
\text { sample }\end{array}$ & 0.93 & 0.64 & 0.03 & 0.12 & 0.03 & 0.55 & 0.27 & 0.03 & 0.52 & 0.35 \\
\hline $\begin{array}{l}\text { First } \\
\text { sample }\end{array}$ & 1.61 & 0.63 & 0.03 & 0.16 & -0.04 & 0.52 & 0.35 & -0.07 & 0.45 & 0.49 \\
\hline $\begin{array}{l}\text { Second } \\
\text { sample }\end{array}$ & 0.60 & 0.29 & 0.03 & 0.09 & 0.06 & 0.23 & 0.23 & 0.08 & 0.24 & 0.25 \\
\hline
\end{tabular}

\subsection{Baseline model estimates based on two releases}

As explained above, the baseline model starts from an $\mathrm{AR}(2)$ model for the underlying inflation process. We prefer to start with only two lags in order to keep the model relatively simple and to facilitate comparison with our previous results obtained in the context of our DSGE model estimation. ${ }^{3}$ As in our previous work, we also plan to test the robustness of the results in a broad set of small forecasting models also including other real-time data series that can serve as proxies for underlying marginal cost (output, unemployment, etc.).

Table 2 contains the model estimates for the baseline model estimated on the first and second release inflation data, with fixed coefficients for alternative setups of the news and noise assumptions. The parameter estimates for the underlying inflation process are very similar in all three variants. The persistence in the inflation process is estimated at around 0.8 , while the constant is around 0.2 , implying an average quarterly inflation rate of $1 \%$. The standard deviation for the fundamental inflation shock is estimated at around 0.35 . Based on this limited dataset, it seems difficult to distinguish between a news or noise interpretation of the data.

\footnotetext{
${ }^{3}$ Alternative tests (t-test, Akaike Information Criterion, Bayesian Information Criterion) for the optimal lag length for a fixed-coefficient autoregressive process in real-time inflation series (regressing the first release on inflation on the lagged inflation rates taken from the same vintage) suggest an $\mathrm{AR}(3)$ model. It remains to be tested whether these results also apply to models with noise-news disturbances and time-varying parameters. Preliminary results suggest that an $\operatorname{AR}(2)$ is sufficient in our set-up.
} 
Table 2. Estimation results for baseline fixed-parameter model estimated on two releases

\begin{tabular}{|c|c|c|c|c|c|c|c|c|c|}
\hline & \multicolumn{3}{|c|}{ Prior distribution } & \multicolumn{6}{|c|}{ Posterior mode } \\
\hline & Distribution & Mean & $\begin{array}{l}\text { Standard } \\
\text { deviation }\end{array}$ & News & & Noise & & News a & nd noise \\
\hline \multirow{2}{*}{$\begin{array}{l}\text { Marginal } \\
\text { likelihood }\end{array}$} & & & & 29.44 & & 29.19 & & 29.64 & \\
\hline & & & & Mode & $\begin{array}{l}\text { Standard } \\
\text { deviation }\end{array}$ & Mode & $\begin{array}{l}\text { Standard } \\
\text { deviation }\end{array}$ & Mode & $\begin{array}{l}\text { Standard } \\
\text { deviation }\end{array}$ \\
\hline$\mu$ & $\mathrm{N}$ & 0.625 & 0.2 & 0.21 & 0.06 & 0.20 & 0.07 & 0.20 & 0.21 \\
\hline$\rho^{1}+\rho^{2}$ & $\mathrm{~N}$ & 0.5 & 0.2 & 0.78 & 0.05 & 0.81 & 0.05 & 0.81 & 0.14 \\
\hline$\rho^{1}-\rho^{2}$ & $\mathrm{~N}$ & 0.3 & 0.1 & 0.27 & 0.07 & 0.28 & 0.09 & 0.28 & 0.26 \\
\hline$\sigma_{\epsilon}$ & IG & 0.1 & 2 & 0.35 & 0.02 & 0.34 & 0.02 & 0.34 & 0.03 \\
\hline$\sigma_{v 1}$ & IG & 0.1 & 2 & 0.12 & 0.01 & & & 0.05 & 0.02 \\
\hline$\sigma_{v 2}$ & IG & 0.1 & 2 & 0.05 & 0.02 & & & 0.05 & 0.02 \\
\hline$\sigma_{\mathrm{s} 1}$ & IG & 0.1 & 2 & & & 0.06 & 0.02 & 0.06 & 0.02 \\
\hline$\sigma_{\varsigma 2}$ & IG & 0.1 & 2 & & & 0.11 & 0.01 & 0.10 & 0.02 \\
\hline
\end{tabular}

Table 3. Estimation results for baseline TVP model estimated on two releases

\begin{tabular}{|c|c|c|c|c|c|c|c|c|c|}
\hline & \multicolumn{3}{|c|}{ Prior distribution } & \multicolumn{6}{|c|}{ Posterior mode } \\
\hline & Distribution & Mean & $\begin{array}{l}\text { Standard } \\
\text { deviation }\end{array}$ & News & & Noise & & News a & nd noise \\
\hline \multirow{2}{*}{$\begin{array}{l}\text { Marginal } \\
\text { likelihood }\end{array}$} & & & & 49.39 & & 49.21 & & 49.27 & \\
\hline & & & & Mode & $\begin{array}{l}\text { Standard } \\
\text { deviation }\end{array}$ & Mode & $\begin{array}{l}\text { Standard } \\
\text { deviation }\end{array}$ & Mode & $\begin{array}{l}\text { Standard } \\
\text { deviation }\end{array}$ \\
\hline$\mu$ & $\mathrm{N}$ & 0.625 & 0.2 & 0.57 & 0.08 & 0.60 & 0.22 & 0.56 & 0.08 \\
\hline$\rho^{1}+\rho^{2}$ & $\mathrm{~B}$ & 0.5 & 0.2 & 0.27 & 0.09 & 0.20 & 0.19 & 0.29 & 0.06 \\
\hline$\rho^{1}-\rho^{2}$ & B & 0.3 & 0.1 & 0.35 & 0.07 & 0.29 & 0.14 & 0.35 & 0.13 \\
\hline$\sigma_{\epsilon}$ & IG & 0.1 & 2 & 0.05 & 0.02 & 0.15 & 0.03 & 0.05 & 0.02 \\
\hline$\sigma_{v 1}$ & IG & 0.1 & 2 & 0.12 & 0.01 & & & 0.05 & 0.04 \\
\hline$\sigma_{v 2}$ & IG & 0.1 & 2 & 0.80 & 0.09 & & & 0.76 & 0.19 \\
\hline$\sigma_{\varsigma 1}$ & IG & 0.1 & 2 & & & 0.08 & 0.02 & 0.08 & 0.02 \\
\hline$\sigma_{\varsigma 2}$ & IG & 0.1 & 2 & & & 0.10 & 0.02 & 0.08 & 0.03 \\
\hline$\sigma_{\mu}$ & IG & 0.1 & 2 & 0.04 & 0.1 & 0.09 & 0.03 & 0.04 & 0.01 \\
\hline$\sigma_{\rho 1}$ & IG & 0.1 & 2 & 0.06 & 0.1 & 0.17 & 0.03 & 0.07 & 0.02 \\
\hline$\sigma_{\rho 2}$ & IG & 0.1 & 2 & 0.04 & 0.1 & 0.04 & 0.01 & 0.04 & 0.01 \\
\hline$\rho$ & $\mathrm{B}$ & 0.5 & 0.28 & 0.95 & 0.2 & 0.99 & 0.01 & 0.94 & 0.02 \\
\hline
\end{tabular}

Table 3 contains the estimated parameters for the baseline model with TVP. The models with TVP clearly outperform the fixed-coefficient model in terms of marginal likelihood. Two properties of the model contribute to this improvement. With a TVP set-up, the covariance matrix for the one-step-ahead forecast errors is also time varying, and this heteroscedasticity correction improves the likelihood of the data. Secondly, the TVP model improves the fit of the model over the second subsample, which corresponds with a period with less volatility in the inflation rate. This feature shows up when we evaluate the RMSE of the forecasts. 
The estimated persistence in the underlying inflation process is very low, which contrasts sharply with the persistence in the fixed-coefficient model. The parameters $\mu$ and $\rho^{1}, \rho^{2}$ now act as initial values and, because we allow the parameters to follow a mean-reverting process, also as long-run steady-state outcomes. The corresponding long-run equilibrium inflation rate is equal to $\mu /\left(1-\rho^{1}-\rho^{2}\right)$. The speed of convergence towards these steady-state values is determined by the overall $\rho$-parameter. At each point in time, we can also consider the implied (or static, for given parameters at some point in time) inflation rate $\mu_{t} /\left(1-\rho_{t}^{1}-\rho_{t}^{2}\right)$. The relevance of this implied inflation rate depends on the convergence speed and on the volatility of the parameter processes. The convergence parameter $\rho$ varies around 0.95 , and the estimated standard deviations for the innovations in the time-varying coefficient processes indicate a strong preference for relatively large fluctuations in the parameters. This time variation substitutes for the estimated persistence in the inflation process. It is clear that a positive update in the constant and the implied inflation expectation following an increase in inflation plays a role very similar to that of high persistence in the underlying inflation process as far as the inflation forecast is concerned.

The overall marginal likelihood of the three models (news, noise, and newsnoise) is similar, but the estimated coefficients indicate that there are some important differences between the models. In the models with news shocks, the size of the fundamental shock is strongly reduced. At the same time, the volatility of the second news shock $\left(\sigma_{v 2}\right)$ is estimated to be very high. This shock suggests that there can be a large divergence between the underlying fundamental inflation rate and the second release on inflation. Together with the small fundamental shock, this combination implies that the estimate of the underlying inflation rate follows a relatively smooth trend that can deviate significantly from the actual data releases. The standard deviation of the first news shock $\left(\sigma_{v 1}\right)$ is estimated precisely and reflects the typical revisions that take place in the second release relative to the first release. The noise shocks act as two iid measurement errors on the two releases.

Figure 1 illustrates the time variation in the constant, the persistence, and the implied equilibrium inflation rate. The persistence increases substantially during the seventies to levels around 0.6 , but with relatively high uncertainty as measured here by the $10 \%$ and $90 \%$ posterior intervals. In the early eighties, inflation persistence declines quickly, and from then onwards, it fluctuates around low values between zero and 0.40 , close to the estimated steady-state value. The constant coefficient $\mu$ remains at a relatively high level in the seventies and declines only in the beginning of the nineties. The correlation between the constant and the persistence is not apparent over time, but there is a strongly negative correlation between the constant and the persistence across different posterior draws: for parameter draws that generate high persistence (for instance, the blue $90 \%$ interval at each point in time in the figure for persistence), we 
observe a very low constant (these draws are also represented by the blue line in the graph for the constant). Similarly, the violet lines illustrate that parameter draws that yield a high constant also generate a low persistence. This negative correlation between persistence and constant explains why the uncertainty around the implied (static) inflation rate is relatively narrowly estimated. Clearly, a higher constant or a higher persistence act as substitutes for producing a similar inflation forecast in the estimated model. This distinction between the role of the constant and the autocorrelation or persistence parameter is related to the inflation-gap concept proposed by Cogley et al. (2010). They assume a random walk behaviour for the parameter processes so that the implied trend inflation is not mean reverting. Their estimation result for the persistence of inflation around this trend inflation is very much in line with our results. ${ }^{4}$

Tables 4 and 5 document the forecasting performance of the fixed and timevarying parameter set-ups. We consider both the performance relative to the first release of inflation, and relative to the SPF forecasts. For both comparisons, we report the bias and the RMSE for the complete sample and for the two subperiods. In terms of forecasting performance, the TVP model does not perform particularly well over the complete sample. The weak performance of the TVP model is concentrated in the first subsample and follows from the high forecast uncertainty implied by the TVP model during that subsample. However, and more importantly, the forecast performance during the second subsample is substantially improved after allowing for time variation. The information from the bias illustrates that the fixed-parameter models were systematically underestimating inflation during the first part of the sample and overpredicting inflation during the second subsample. The TVP model reduces these major systematic forecasting errors, especially during the second sample. This is most evident in the model with noise.

An important question is whether adding the SPF forecasts as additional observables to the model allows a reduction in the estimation uncertainty around the parameters. Thus, we compare first the implied forecasts of our simple models with those of the SPF in terms of bias, RMSE error, and actual forecast outcome. Next, we also perform a marginal probability test to show that the augmented model with three observables, including the SPF forecast information, better allows the fitting of the two actual releases of inflation than the model estimated on these two series alone. In terms of resemblance to the SPF forecasts, we may note that the deviation between the model forecasts and the SPF forecasts, both in terms of RMSE and bias, is relatively small. The bias measures illustrate that the deviation between the forecasts from the TVP and the fixed model is at least as important as the deviations between the TVP model and the SPF forecasts. The fixed-parameter model predicts systematically higher inflation than the SPF forecasts during the second subsample, while the reverse holds for the TVP models.

\footnotetext{
${ }^{4}$ In the NBER WP version (N 13749) of their paper, they report an estimate for the persistence in the context of a univariate model.
} 
Figure 1. Time variation in persistence, constant, and implied inflation rate according to baseline model

Persistence $\left(\rho_{t}^{1}+\rho_{t}^{2}\right)$

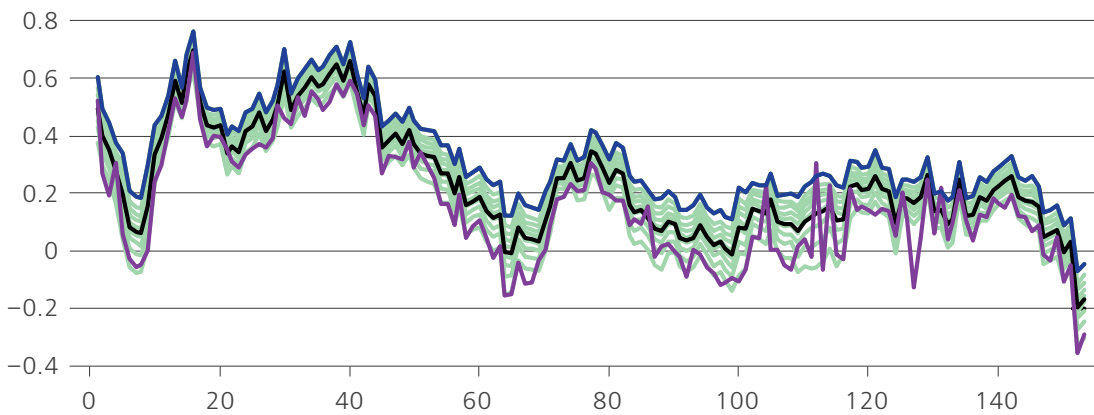

— posterior distribution, 90th percentile of inflation persistence

- posterior distribution, median of inflation persistence

— 10th, 20th, ... 90th percentile of posterior distribution of inflation persistence

— persistence corresponding to the 90th percentile of constant

Constant $\mu_{t}$

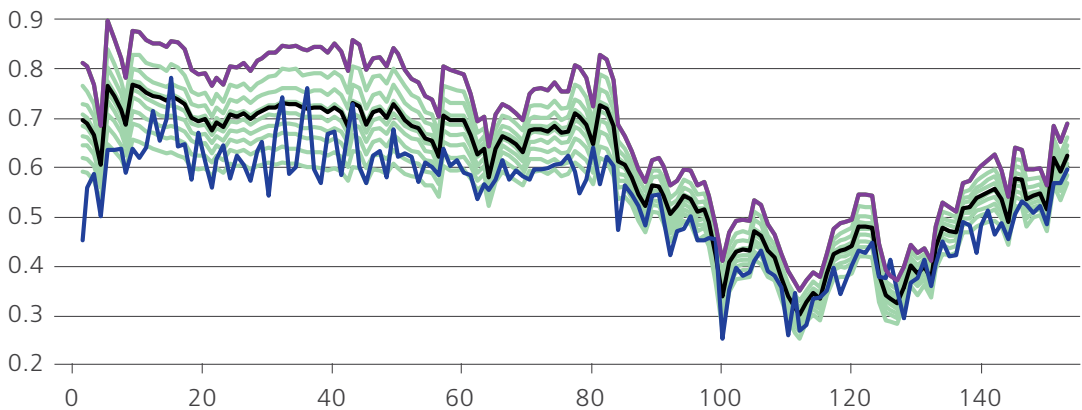

_ value of constant, corresponding to 90th percentile of the inflation persistence

- posterior distribution, median of the constant

— 10th, 20th, ... 90th percentles of the posterior distribution of constant

— posterior distribution, 90th percentile of the constant

Implied (static) inflation rate $\mu_{t} /\left(1-\rho^{1}-\rho^{2}\right)$

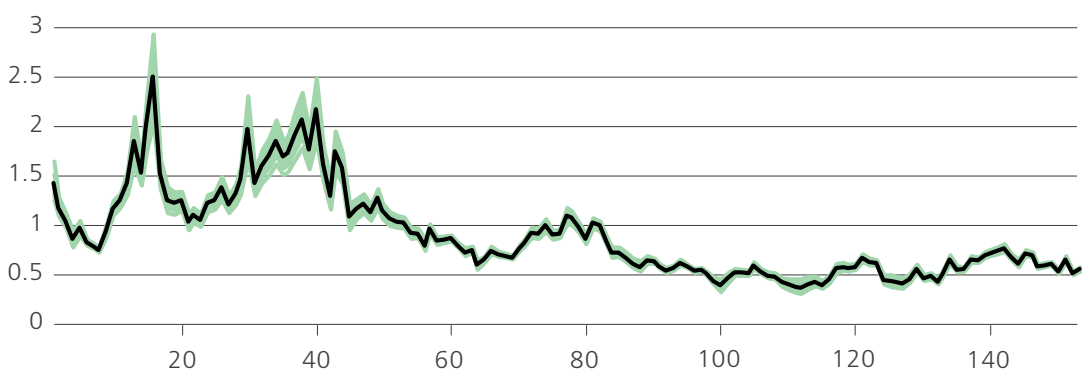

- posterior distribution, median of static inflation rate

— 10th, 20th, ... 90th percentiles of posterior distribution of static inflation rate 
The marginal likelihood test confirms that adding the SPF forecast information to the estimation of the baseline model helps to reduce the uncertainty in the estimation of the model. In other words, we cannot reject the hypothesis that the simple autoregressive model is the underlying forecasting model used by the survey forecasters. Table 6 shows that, indeed, the marginal likelihood of the two releases of inflation is higher when conditioning the model on the SPF forecast: $\mathrm{P}\left(y_{t}^{t+1}, y_{t-1}^{t+1} \mid y_{t+1}^{n}, \theta\right)$ exceeds $\mathrm{P}\left(y_{t}^{t+1}, y_{t-1}^{t+1} \mid \theta\right)$ by an important factor. We discuss the estimates for the augmented model with SPF forecasts in detail in the next section. One can also note that the explanatory power of the model for the forecast data also increases if the model is conditioned on actual observed releases, similarly to Del Negro and Eusepi (2011).

Table 4. Forecast performance of fixed-parameter baseline models

\begin{tabular}{|c|c|c|c|c|c|c|}
\hline & \multicolumn{2}{|l|}{ News } & \multicolumn{2}{|l|}{ Noise } & \multicolumn{2}{|c|}{ News and noise } \\
\hline & RMSE & Bias & RMSE & Bias & RMSE & Bias \\
\hline \multicolumn{7}{|c|}{ Relative to first release (zero-quarter-ahead / one-quarter-ahead) } \\
\hline Complete sample & $0.35 / 0.40$ & $0.01 / 0.01$ & $0.35 / 0.40$ & $0.03 / 0.05$ & $0.35 / 0.40$ & $0.03 / 0.04$ \\
\hline Subsample 1 & $0.48 / 0.57$ & $-0.13 /-0.22$ & $0.47 / 0.56$ & $-0.09 /-0.16$ & $0.47 / 0.56$ & $-0.10 /-0.17$ \\
\hline Subsample 2 & $0.27 / 0.29$ & $0.08 / 0.12$ & $0.28 / 0.30$ & $0.09 / 0.15$ & $0.28 / 0.30$ & $0.09 / 0.14$ \\
\hline \multicolumn{7}{|c|}{ Relative to SPF (zero-quarter-ahead / one-quarter-ahead) } \\
\hline Complete sample & $0.20 / 0.22$ & $-0.02 /-0.02$ & $0.20 / 0.21$ & $0.01 / 0.02$ & $0.20 / 0.21$ & $0.00 / 0.01$ \\
\hline Subsample 1 & $0.28 / 0.29$ & $-0.10 /-0.15$ & $0.27 / 0.26$ & $-0.06 /-0.09$ & $0.27 / 0.27$ & $-0.06 /-0.01$ \\
\hline Subsample 2 & $0.14 / 0.17$ & $0.02 / 0.04$ & $0.15 / 0.18$ & $0.04 / 0.07$ & $0.15 / 0.17$ & $0.03 / 0.06$ \\
\hline
\end{tabular}

Note: In this table, we compare the model prediction formed at time $t$ for time $t+1 / t+2$ with the SPF zeroquarter-ahead nowcast / one-quarter-ahead forecast.

Table 5. Forecast performance of time-varying baseline models

\begin{tabular}{lllllll} 
& \multicolumn{2}{l}{ News } & Noise & \multicolumn{2}{l}{ News and noise } \\
& RMSE & Bias & RMSE & Bias & RMSE & Bias \\
\hline \multicolumn{7}{l}{ Relative to first release (zero-quarter-ahead / one-quarter-ahead) } \\
\hline Complete sample & $0.34 / 0.40$ & $-0.01 /-0.03$ & $0.36 / 0.44$ & $0.03 / 0.03$ & $0.34 / 0.40$ & $0.01 /-0.01$ \\
\hline Subsample 1 & $0.49 / 0.61$ & $-0.10 /-0.20$ & $0.52 / 0.68$ & $0.03 / 0.04$ & $0.48 / 0.60$ & $-0.09 /-0.18$ \\
\hline Subsample 2 & $0.24 / 0.25$ & $0.04 / 0.05$ & $0.24 / 0.26$ & $0.03 / 0.03$ & $0.24 / 0.25$ & $0.05 / 0.06$ \\
\hline Relative to SPF (zero-quarter-ahead / one-quarter-ahead) \\
\hline Complete sample & $0.20 / 0.19$ & $-0.03 /-0.06$ & $0.25 / 0.27$ & $0.00 / 0.00$ & $0.19 / 0.19$ & $-0.02 /-0.04$ \\
\hline Subsample 1 & $0.28 / 0.27$ & $-0.07 /-0.13$ & $0.36 / 0.43$ & $0.06 / 0.11$ & $0.29 / 0.28$ & $-0.05 /-0.11$ \\
\hline Subsample 2 & $0.13 / 0.13$ & $-0.02 /-0.03$ & $0.17 / 0.14$ & $-0.03 /-0.05$ & $0.13 / 0.13$ & $0.00 /-0.02$ \\
\hline
\end{tabular}

Table 6. Marginal likelihood test on forecasting models

\begin{tabular}{lllllll} 
& \multicolumn{2}{l}{ Fix-parameter model } & \multicolumn{2}{l}{ TVP-model } \\
& News & Noise & News and noise & News & Noise & News and noise \\
\hline $\mathrm{P}\left(y_{t}^{t+1}, y_{t-1}^{t+1} \mid \theta\right)$ & 29.44 & 29.19 & 29.64 & 44.77 & 49.20 & 42.76 \\
\hline $\mathrm{P}\left(y_{t}^{t+1}, y_{t-1}^{t+1} \mid y_{t+1}^{n}, \theta\right)$ & 64.58 & & & 68.35 & 74.79 & 76.36 \\
\hline $\mathrm{P}\left(y_{t}^{t+1}, y_{t-1}^{t+1} \mid y_{t+1}^{n}, \theta\right)$ & 106.09 & 64.42 & 110.76 & 141.88 & 148.65 & 149.05 \\
\hline $\mathrm{P}\left(y_{t+1}^{n} \mid \theta\right)$ & 41.51 & & & 73.53 & 73.86 & 72.69 \\
\hline $\mathrm{P}\left(y_{t+1}^{n} \mid y_{t}^{t+1}, y_{t-1}^{t+1}, \theta\right)$ & 76.65 & & & 97.11 & 99.45 & 106.29
\end{tabular}




\subsection{Augmented model estimates based on two releases and SPF forecasts}

Table 7 reports the estimated parameters for the model estimated with the SPF zero-quarter-ahead forecast included in the observable dataset. Compared to the estimation results of the baseline model based on two-release data only reported in Table 3, we observe that several parameters are now estimated with higher precision. It is also important that the additional measurement error on the forecast observable is estimated to be very small. ${ }^{5}$ This confirms that the survey forecasts are in line with the model predictions. The estimated parameters for the underlying inflation process and the volatility of the fundamental shock are now very similar across the three model versions. The standard deviations of the parameter innovations are now smaller but estimated with high precision. The meanreversion coefficient in the parameters is slightly reduced, to 0.93 in all three versions of the model. Overall, the estimation results of the augmented model are in line with the baseline estimates, but they allow estimation of the model with more precision and higher consistency across different specifications. A similar result is observed when higher horizon forecasts are included in the list of observables. The same trends are also obvious in the estimated parameters of the fixed-parameter model augmented with SPF forecasts as observables, but the marginal likelihood of the model remains largely below that of the TVP set-up.

The forecasting statistics summarised by the RMSE and bias relative to the firstrelease data confirm that the augmented model fits the data much better and with relatively similar outcomes across models. The magnitude of the systematic bias is also reduced. The comparison of the model forecasts with the SPF forecasts is now based on one-quarter-ahead forecasts, because the nowcasts are part of the information set of the model in this application. Given this information, our model forecasts match closely with the SPF for the one-quarter-ahead and even for the four-quarter-ahead forecasts. Especially in the second subsample, the model and the SPF forecast behave very similarly, with a small RMS deviation and no systematic bias between the two forecasts. For the complete sample, the results are still similar for the fixed and TVP models, suggesting that most of the improved likelihood is related to the uncertainty of time-varying prediction. The TVP model outperforms the fixed-parameter version in forecasting actual realisations during the more recent subsample both in terms of RMSE and bias. This dominance is most obvious in the longer-horizon forecasts. In terms of comparison with the SPF forecasts, the TVP model clearly performs better than the fixed-parameter model for all subperiods and all criteria. From these results, we can conclude that the integration of the SPF data into the TVP model estimation guarantees that the model dynamics can be considered a relative precise approximation of the forecasters' beliefs.

\footnotetext{
${ }^{5}$ The priors that are used in these estimations prevent the estimates for the standard errors of the shocks from approaching zero. Re-estimation with a more intelligent prior is necessary.
} 
Table 7. Estimation results for augmented model estimated on two releases and zero-quarter-ahead forecast with TVP

\begin{tabular}{|c|c|c|c|c|c|c|c|c|c|}
\hline & \multicolumn{3}{|c|}{ Prior distribution } & \multicolumn{6}{|c|}{ Posterior mode } \\
\hline & Distribution & Mean & $\begin{array}{l}\text { Standard } \\
\text { deviation }\end{array}$ & News & & Noise & & News a & ad noise \\
\hline \multirow{2}{*}{$\begin{array}{l}\text { Marginal } \\
\text { likelihood }\end{array}$} & & & & 141.88 & & 148.65 & & 149.05 & \\
\hline & & & & Mode & $\begin{array}{l}\text { Standard } \\
\text { deviation }\end{array}$ & Mode & $\begin{array}{l}\text { Standard } \\
\text { deviation }\end{array}$ & Mode & $\begin{array}{l}\text { Standard } \\
\text { deviation }\end{array}$ \\
\hline$\mu$ & $\mathrm{N}$ & 0.625 & 0.2 & 0.54 & 0.05 & 0.69 & 0.06 & 0.70 & 0.06 \\
\hline$\rho^{1}+\rho^{2}$ & B & 0.5 & 0.2 & 0.22 & 0.05 & 0.16 & 0.06 & 0.16 & 0.05 \\
\hline$\rho^{1}-\rho^{2}$ & B & 0.3 & 0.1 & 0.15 & 0.04 & 0.17 & 0.03 & 0.17 & 0.05 \\
\hline$\sigma_{\epsilon}$ & IG & 0.1 & 2 & 0.27 & 0.02 & 0.25 & 0.02 & 0.26 & 0.02 \\
\hline$\sigma_{v 1}$ & IG & 0.1 & 2 & 0.12 & 0.01 & & & 0.05 & 0.02 \\
\hline$\sigma_{v 2}$ & IG & 0.1 & 2 & 0.38 & 0.04 & & & 0.05 & 0.02 \\
\hline$\sigma_{\varsigma 1}$ & IG & 0.1 & 2 & & & 0.07 & 0.02 & 0.07 & 0.02 \\
\hline$\sigma_{\varsigma 2}$ & IG & 0.1 & 2 & & & 0.10 & 0.01 & 0.09 & 0.02 \\
\hline$\sigma_{n}$ & IG & 0.1 & 2 & 0.03 & 0.01 & 0.04 & 0.01 & 0.04 & 0.01 \\
\hline$\sigma_{\mu}$ & IG & 0.1 & 2 & 0.03 & 0.01 & 0.08 & 0.01 & 0.08 & 0.01 \\
\hline$\sigma_{\rho 1}$ & IG & 0.1 & 2 & 0.04 & 0.01 & 0.08 & 0.01 & 0.08 & 0.01 \\
\hline$\sigma_{\rho 2}$ & IG & 0.1 & 2 & 0.03 & 0.01 & 0.04 & 0.01 & 0.04 & 0.01 \\
\hline$\rho$ & $\mathrm{B}$ & 0.5 & 0.28 & 0.94 & 0.02 & 0.93 & 0.02 & 0.93 & 0.02 \\
\hline
\end{tabular}

Table 8. Forecast performance of augmented forecasting models with fixed parameters

\begin{tabular}{|c|c|c|c|c|c|c|}
\hline & \multicolumn{2}{|l|}{ News } & \multicolumn{2}{|l|}{ Noise } & \multicolumn{2}{|c|}{ News and noise } \\
\hline & RMSE & Bias & RMSE & Bias & RMSE & Bias \\
\hline \multicolumn{7}{|c|}{ Relative to first release (one-quarter-ahead) } \\
\hline Complete sample & $0.36 / 0.46$ & $0.03 / 0.03$ & 0.35 & 0.04 & $0.36 / 0.45$ & $0.04 / 0.05$ \\
\hline Subsample 1 & $0.51 / 0.66$ & $-0.14 /-0.36$ & 0.49 & -0.08 & $0.50 / 0.64$ & $-0.12 /-0.31$ \\
\hline Subsample 2 & $0.26 / 0.32$ & $0.11 / 0.21$ & 0.25 & 0.10 & $0.26 / 0.33$ & $0.12 / 0.22$ \\
\hline \multicolumn{7}{|c|}{ Relative to SPF (one-quarter-ahead) } \\
\hline Complete sample & $0.14 / 0.24$ & $0.00 / 0.00$ & 0.12 & 0.01 & $0.14 / 0.22$ & $0.01 / 0.02$ \\
\hline Subsample 1 & $0.19 / 0.34$ & $-0.07 /-0.26$ & 0.15 & -0.01 & $0.18 / 0.29$ & $-0.05 /-0.21$ \\
\hline Subsample 2 & $0.11 / 0.18$ & $0.03 / 0.12$ & 0.09 & 0.02 & $0.11 / 0.18$ & $0.04 / 0.13$ \\
\hline
\end{tabular}

Table 9. Forecast performance of augmented forecasting models with TVP

\begin{tabular}{|c|c|c|c|c|c|c|}
\hline & \multicolumn{2}{|l|}{ News } & \multicolumn{2}{|l|}{ Noise } & \multicolumn{2}{|c|}{ News and noise } \\
\hline & RMSE & Bias & RMSE & Bias & RMSE & Bias \\
\hline \multicolumn{7}{|c|}{ Relative to first release (one-quarter-ahead / four-quarter-ahead) } \\
\hline Complete sample & $0.36 / 0.44$ & $0.01 /-0.05$ & 0.35 & 0.03 & $0.35 / 0.42$ & $0.03 / 0.00$ \\
\hline Subsample 1 & $0.52 / 0.68$ & $-0.14 /-0.35$ & 0.50 & -0.09 & $0.50 / 0.63$ & $-0.09 /-0.24$ \\
\hline Subsample 2 & $0.25 / 0.27$ & $0.08 / 0.09$ & 0.25 & 0.08 & $0.25 / 0.28$ & $0.08 / 0.11$ \\
\hline \multicolumn{7}{|c|}{ Relative to SPF (one-quarter-ahead / four-quarter-ahead) } \\
\hline Complete sample & $0.11 / 0.19$ & $-0.02 /-0.08$ & 0.13 & -0.00 & $0.13 / 0.16$ & $-0.00 /-0.03$ \\
\hline Subsample 1 & $0.16 / 0.31$ & $-0.07 /-0.26$ & 0.19 & -0.02 & $0.18 / 0.25$ & $-0.02 /-0.14$ \\
\hline Subsample 2 & $0.09 / 0.10$ & $0.00 / 0.00$ & 0.09 & -0.01 & $0.09 / 0.10$ & $0.01 / 0.02$ \\
\hline
\end{tabular}


Figure 2. Time variation in persistence, constant, and implied inflation rate according to augmented model

Persistence $\left(\rho_{t}^{1}+\rho_{t}^{2}\right)$

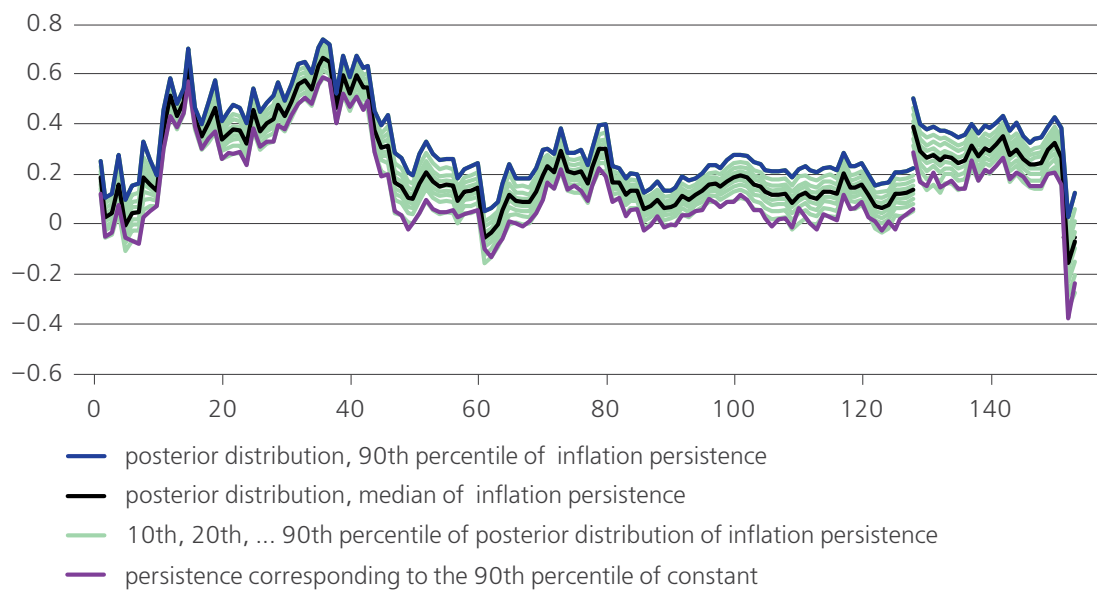

Constant $\mu_{t}$

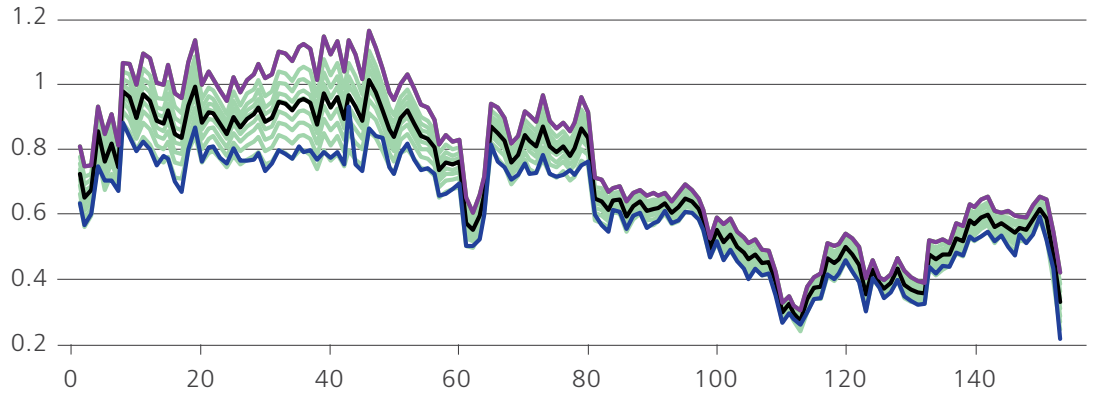

_ value of constant, corresponding to 90th percentile of the inflation persistence

— posterior distribution, median of the constant

— 10th, 20th, ... 90th percentles of the posterior distribution of constant

— posterior distribution, 90th percentile of the constant

Implied (static) inflation rate $\mu_{t} /\left(1-\rho_{t}^{1}-\rho_{t}^{2}\right)$

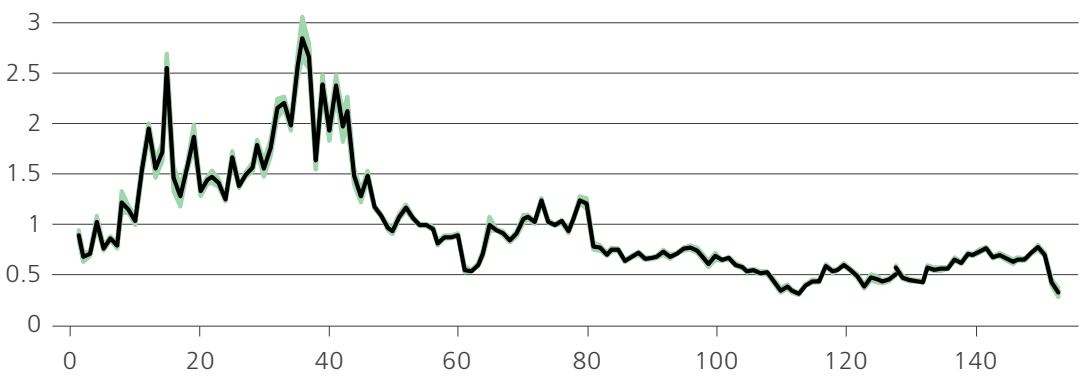

— posterior distribution, median of static inflation rate

— 10th, 20th, ... 90th percentiles of posterior distribution of static inflation rate 
Figure 2 illustrates the time variation that is estimated in the augmented TVP model. The patterns are very similar to those observed in the baseline model. In contrast to the large uncertainty around the constant and the persistence, the uncertainty around the implied (static) inflation rate is very small. This means that high values for the constant go together with low values for the persistence, and the other way around. This uncertainty around the implied inflation rate is further reduced in the augmented model compared to the baseline model.

\subsection{Augmented model estimates with additional SPF forecasts}

In this section, we illustrate that the estimation results of the model remain robust when we include additional SPF forecasts with longer horizons in the list of observables. Table 10 summarises the parameter estimates of this extension of the TVP model with a news specification for real-time data revisions.

Table 10. Estimation results for augmented model (TVP-news version) with longer-horizon forecasts

\begin{tabular}{|c|c|c|c|c|c|c|c|c|}
\hline & \multicolumn{8}{|c|}{ Posterior mode } \\
\hline & \multicolumn{2}{|c|}{ Zero-quarter } & \multicolumn{2}{|c|}{ One-quarter } & \multicolumn{2}{|c|}{ Two-quarters } & \multicolumn{2}{|c|}{ Four-quarters } \\
\hline \multirow{2}{*}{$\begin{array}{l}\text { Marginal } \\
\text { likelihood }\end{array}$} & 141.88 & & 298.69 & & 448.99 & & 734.03 & \\
\hline & Mode & $\begin{array}{l}\text { Standard } \\
\text { deviation }\end{array}$ & Mode & $\begin{array}{l}\text { Standard } \\
\text { deviation }\end{array}$ & Mode & $\begin{array}{l}\text { Standard } \\
\text { deviation }\end{array}$ & Mode & $\begin{array}{l}\text { Standard } \\
\text { deviation }\end{array}$ \\
\hline$\mu$ & 0.54 & 0.05 & 0.72 & 0.17 & 0.66 & 0.09 & 0.59 & 0.05 \\
\hline$\rho^{1}+\rho^{2}$ & 0.22 & 0.05 & 0.13 & 0.05 & 0.13 & 0.04 & 0.22 & 0.04 \\
\hline$\rho^{1}-\rho^{2}$ & 0.15 & 0.04 & 0.18 & 0.08 & 0.07 & 0.03 & 0.08 & 0.05 \\
\hline$\sigma_{\epsilon}$ & 0.27 & 0.02 & 0.28 & 0.02 & 0.27 & 0.02 & 0.27 & 0.02 \\
\hline$\sigma_{v 1}$ & 0.12 & 0.01 & 0.12 & 0.01 & 0.12 & 0.01 & 0.12 & 0.01 \\
\hline$\sigma_{v 2}$ & 0.38 & 0.04 & 0.31 & 0.04 & 0.46 & 0.06 & 0.43 & 0.04 \\
\hline$\sigma_{n}$ & 0.03 & 0.01 & 0.04 & 0.01 & 0.05 & 0.00 & 0.05 & 0.00 \\
\hline$\sigma_{f 1}$ & & & 0.04 & 0.01 & 0.05 & 0.00 & 0.05 & 0.00 \\
\hline$\sigma_{f 2}$ & & & & & 0.07 & 0.01 & 0.07 & 0.00 \\
\hline$\sigma_{f 3}$ & & & & & & & 0.07 & 0.01 \\
\hline$\sigma_{f 4}$ & & & & & & & 0.10 & 0.01 \\
\hline$\sigma_{\mu}$ & 0.03 & 0.01 & 0.06 & 0.01 & 0.04 & 0.01 & 0.03 & 0.00 \\
\hline$\sigma_{\rho 1}$ & 0.04 & 0.01 & 0.05 & 0.01 & 0.03 & 0.00 & 0.03 & 0.00 \\
\hline$\sigma_{\rho 2}$ & 0.03 & 0.01 & 0.03 & 0.01 & 0.04 & 0.01 & 0.03 & 0.00 \\
\hline$\rho$ & 0.94 & 0.02 & 0.94 & 0.02 & 0.94 & 0.01 & 0.95 & 0.01 \\
\hline
\end{tabular}

Two results are interesting to note. The parameter estimates remain stable in moving from a three-variable setting (two releases plus nowcast) to the complete set of seven observables (two releases plus nowcast plus four forecasts). 
The measurement error on the forecasts increases only slightly as the horizon becomes longer. As we have concluded already from the longer-horizon forecast results, our simple forecasting models seem able to give a relatively good description of the complete dynamics of the SPF forecasts at least up to a horizon of one-year. It is also noteworthy that the estimated parameter persistence is not affected by the longer-horizon information: the parameter increases from 0.94 to 0.95 and is estimated with high precision. The mean-reverting tendency in the parameters that is implied by this persistence seems to be consistent with the longer-horizons forecasts as well.

Figure 3 shows the corresponding beliefs of these TVP-news models estimated with different horizons. The figures confirm that the implied beliefs are very stable across models.

Figure 3. Time variation in persistence and constant for augmented model estimated with longer horizon forecast

Persistence $\left(\rho_{t}^{1}+\rho_{t}^{2}\right)$

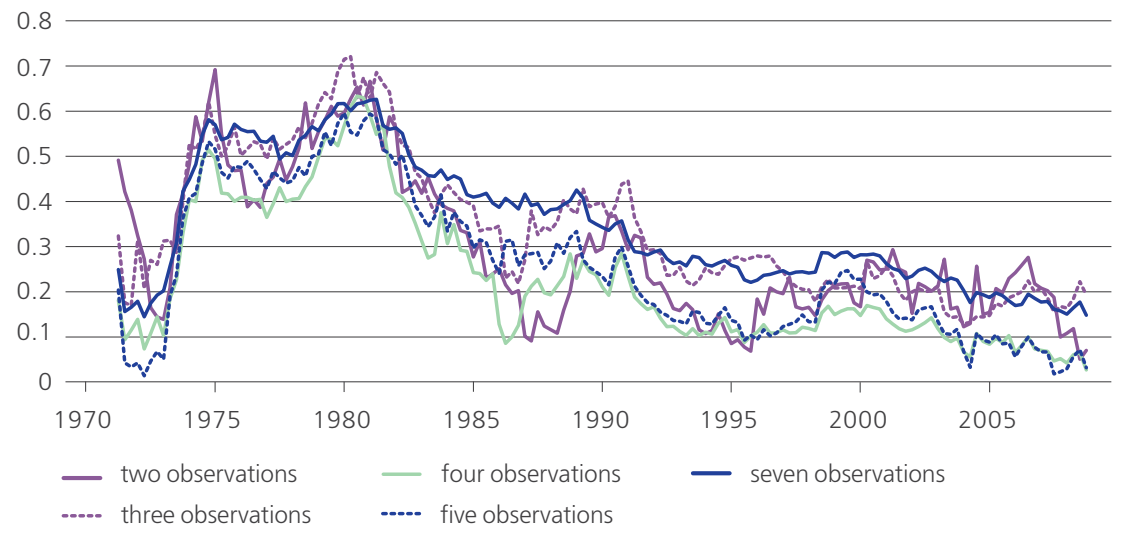

Constant $\mu_{t}$

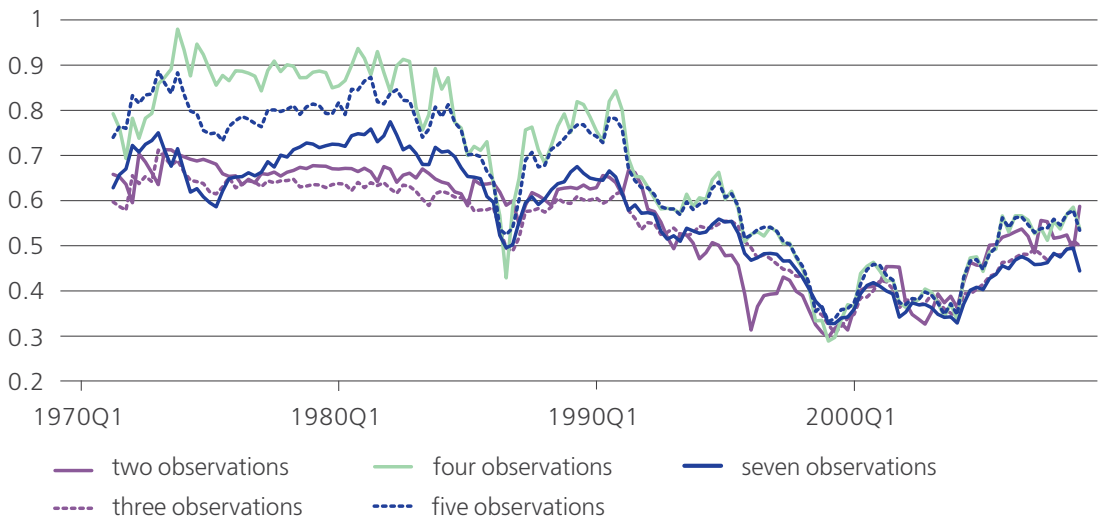




\section{Comparison with DSGE learning results}

In our earlier paper (Slobodyan and Wouters, 2012b), we estimated the beliefs of economic agents in the context of a medium-sized DSGE model. We assumed that agents' forecasts were formulated based on small models and that agents updated their beliefs using Kalman filter learning. In the baseline version, we also used an $\mathrm{AR}(2)$ specification for the beliefs, but we illustrated that the results were robust when using alternative small models, for instance, small VAR models. In contrast with the present paper, these beliefs were estimated on final data, and no survey information was used to estimate the forecasting model. In this context, we found robust behaviour in the perceived persistence and the constant in the inflation forecasting model. Figure 4 compares the time variation in these belief coefficients with the time-varying parameters that we estimated in this paper. The first example from the DSGE model is taken from the baseline model in Slobodyan and Wouters (2012b). In this baseline model, the priors on the belief coefficients and the secondmoment matrices were consistent with the corresponding rational expectations equilibrium. The second example selected from the DSGE paper corresponds with the optimised-belief model (see Table 8 in Slobodyan and Wouters (2012b), 'Optimized beliefs, V from AL DSGE'). This result was obtained from a model in which the prior beliefs were estimated in order to maximise the posterior likelihood of the overall model. This optimisation over initial beliefs produced a significantly higher marginal likelihood. We compare this time variation with the results from the baseline two-variable model (release data only) and the augmented three-variable model (including the SPF nowcast in the dataset).

The figure illustrates that the profile in the estimated persistence and the constant behaves very similarly in all these models. The persistence follows the same profile in all four models, with peak values in the mid and late seventies, followed by a quick decrease in the early eighties. In the baseline DSGE model, the persistence remained at a higher level during the second subsample because this was imposed by the prior derived from the rational expectations DSGE model. The DSGE model with optimised prior allowed the persistence to decline much more. While we were reluctant to give too much weight to this optimised prior belief version in the DSGE paper, because it implied larger deviations from the rational expectations restrictions, it turns out now that the beliefs implied by this best-fitting DSGE model are also those most consistent with the time-varying parameters detected in this paper, based on real-time data and SPF forecasts.

The persistence in the baseline DSGE model is estimated at the upper bound of the typical posterior intervals that we estimate in this paper. This high persistence close to one is difficult to harmonise with a basic feature of the 
SPF forecasts, their standard deviation, which is low compared to the actual inflation releases. With a near-random-walk belief model, the forecasts should have a volatility similar to that of the actual data releases unless there is a considerable correction for noise in agents' estimates of the true underlying inflation process, but the combination of modest persistence and relatively high sensitivity of the constant (or implied inflation expectation) produces an outcome that is very similar to a model with high inflation persistence. In that sense, the results in this paper are completely consistent with the expectations models detected in our DSGE models with learning.

Figure 4. Comparison of time variation in persistence and constant with DSGE model estimates

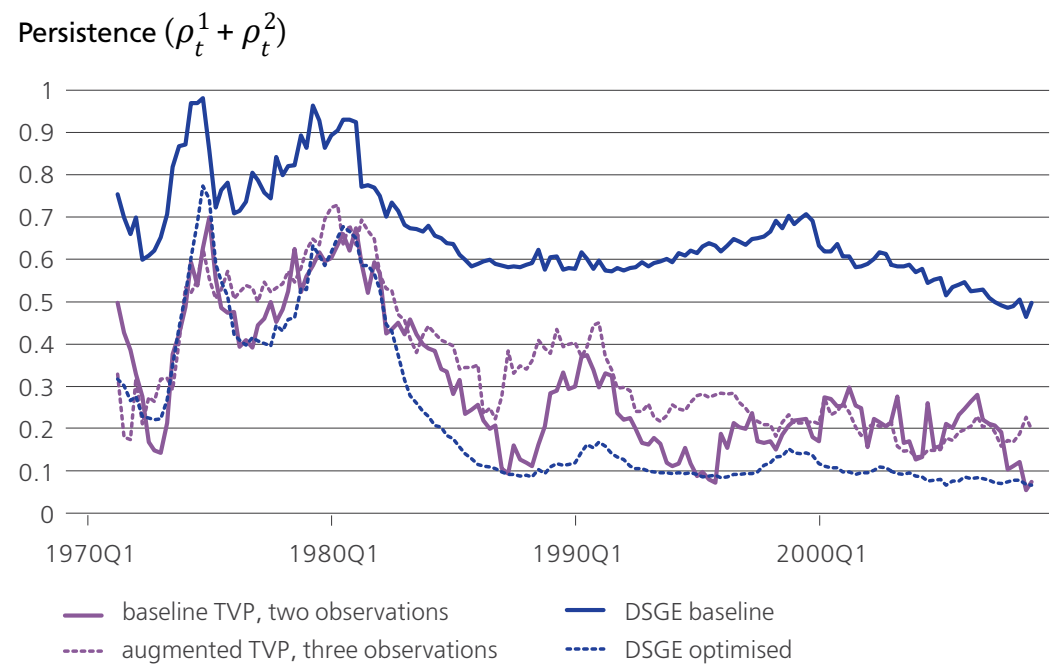

Constant $\mu_{t}$

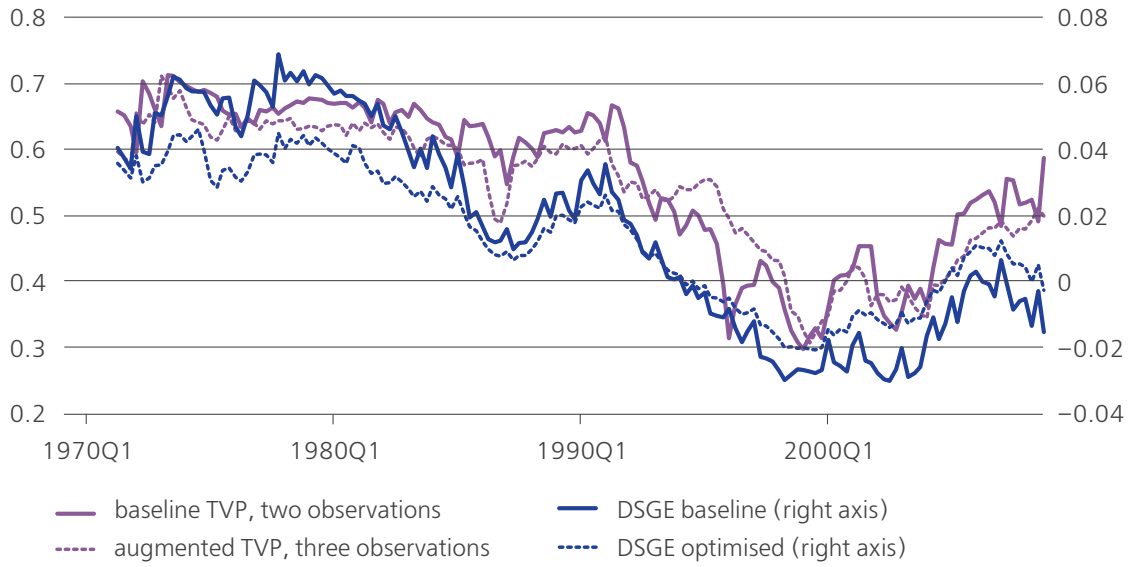




\section{Impulse response functions: How beliefs adjust after an inflation shock}

Figure 5 illustrates the impulse response function (IRF) of a news shock on inflation and the underlying parameters of the model for five different dates in our sample. This particular exercise is based on the news version of the augmented model, estimated with three observables (two releases and the nowcast). The pictures for the fundamental shock and for the other model versions yield qualitatively similar outcomes. The five data points at which the IRFs are evaluated correspond with 1974Q4, 1980Q4, 1986Q4, 1995Q4, and 2001Q4. For each of these five data points, we plot the reactions of inflation and the parameters over the following 20 quarters. The green lines represent the $10 \%$ to $90 \%$ posterior deciles. Each shock represents a one-standard-deviation innovation. In calculating the IRF of these shocks, we take into account the filtering problem and the non-linear nature of the model. Based on the time-varying Kalman gain matrix, agents come up with different estimates for the innovation of the shock through time. Subsequently, the time-varying parameters also change the propagation of the shock.

In terms of the inflation response, it is clear that the shock had a more persistent impact on inflation during the first half of the sample. Until the early eighties, the responses display a hump shaped reaction with a peak effect sometimes up to three quarters after the initial disturbance. In the nineties, on the other hand, the response is completely different, with a very fast decline after the initial impact effect. So, the IRF on inflation is more complex than would be expected based on the estimated persistence only: as illustrated before, this persistence was higher in the first subsample, but it remained modest and far below one. The complete reaction of inflation, especially during the first subsample, seems very much affected by the updating in the coefficients.

These effects are summarised by the implied (static) inflation rate, which combines the impact of the constant and the persistence. This static inflation expectation is very sensitive to the shock in the first subsample. Updating in persistence is clearly the dominating force during that period, but the uncertainty around the estimated persistence is large. The specific reactions of persistence and the constant act as close substitutes: for parameter draws that generate a large adjustment in the persistence (the top violet decile for persistence), the adjustment in the constant is typically low or even negative, while the opposite applies as well (see the top blue decile for the constant). During the more recent period, the overall level of the estimated persistence in inflation was very low, and small adjustments around that level are no longer important for the inflation forecast, and as a consequence, these adjustments are no longer significantly estimated. Updates in the constant are better identified during that period, but the magnitude of these adjustments remains relatively small, which translates into very small inflation responses once the impact effect has passed. 
Figure 5. IRF of news shock on inflation and forecasting parameters in augmented model with TVP Inflation $\left(\tilde{y}_{t}\right)$

0.25

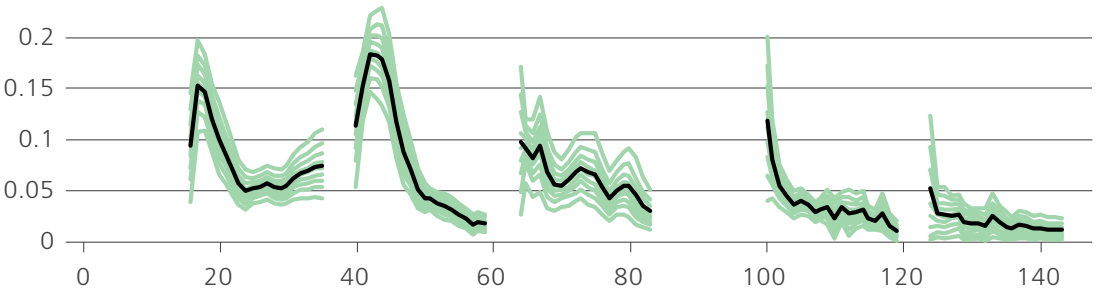

- median of posterior distribution of the impulse response

— 10th, 20th, ... 90th percentiles of posterior distribution of impulse response

Static inflation rate $\mu_{t} /\left(1-\rho_{t}^{1}-\rho_{t}^{2}\right)$

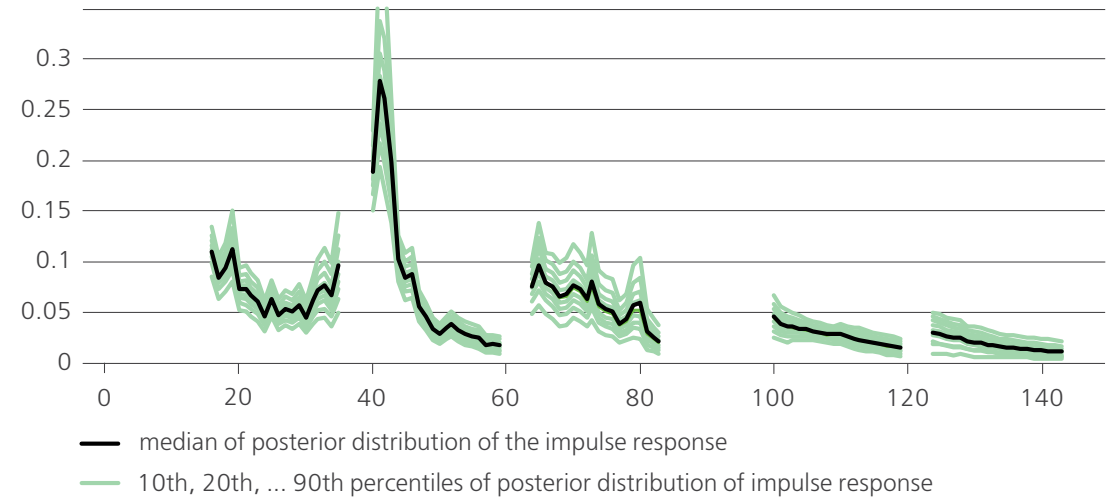

Persistence $\left(\rho_{t}^{1}+\rho_{t}^{2}\right)$

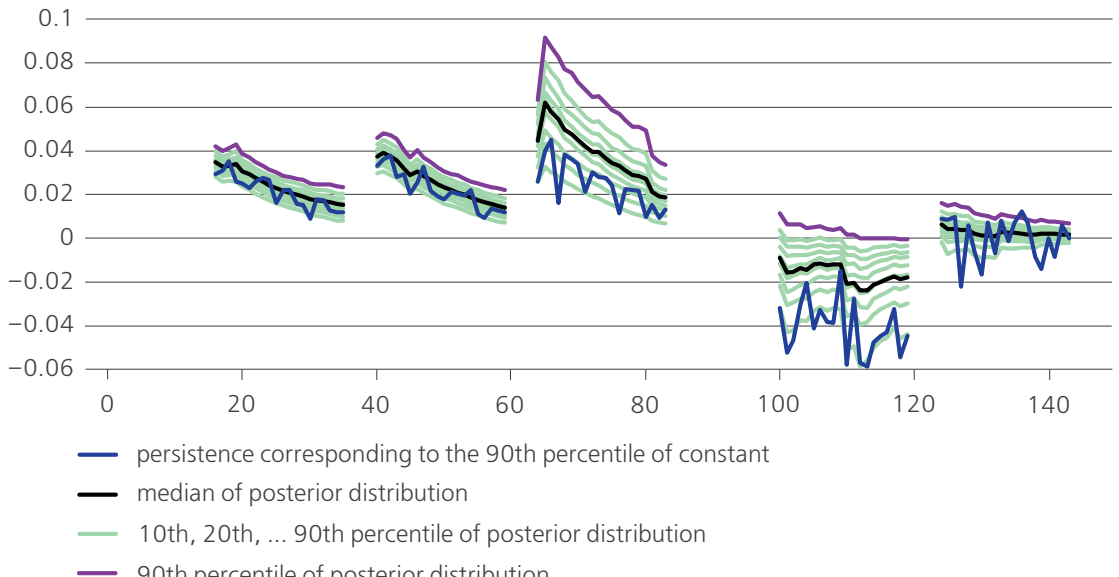

Figure 5 continued on p. 26 


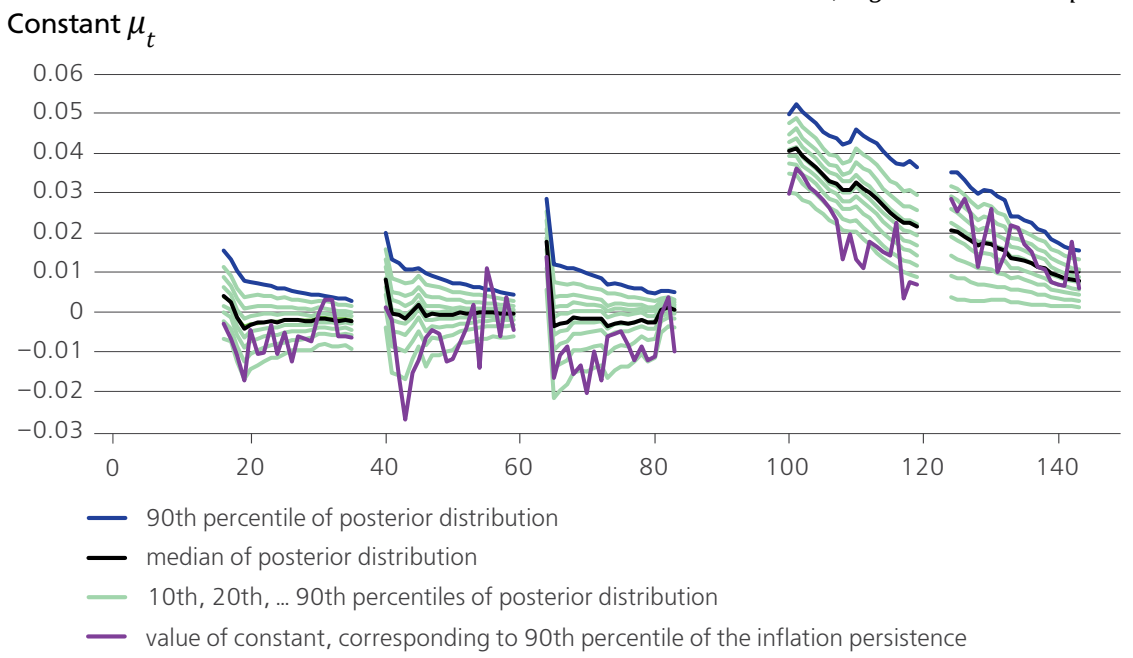

\section{Conclusions}

In this paper, we compare the time variability of parameters in univariate statistical models of inflation with the time-variation produced by the adaptive learning updating in medium-scale DSGE models. Our estimation results clearly illustrate the importance of time-varying parameters in statistical models of the inflation process. Survey of Professional Forecasters data on inflation expectations are consistent with these TVP models; furthermore, treating these survey data as observables for the inflation forecasts helps to pin down more precisely the time-varying path of the parameters. Such an exercise requires the use of real-time data and news/noise specifications in the measurement error process. The resulting time variation in the mean and persistence of the inflation process in the univariate TVP statistical models is consistent with the parameter updating dynamics that are produced by adaptive learning in structural DSGE models. These results validate the use of the adaptive learning hypothesis as an appropriate alternative for the standard fixed-coefficient rational expectations hypothesis in structural DSGE models.

\section{References}

Branch, W. A. and Evans, G. W. (2006). A Simple Recursive Forecasting Model. Economics Letters, 91(2), pp. 158-166. https://doi.org/10.1016/j.econlet.2005.09.005

Cogley, T., Primiceri, G. E. and Sargent, T. J. (2010). Inflation-Gap Persistence in the U.S. American Economic Journal: Macroeconomics, 2(1), pp. 43-69. https://doi.org/10.1257/mac.2.1.43

Croushore, D. (2011). Frontiers of Real-Time Data Analysis. Journal of Economic Literature, 49(1), pp. 72-100. https://doi.org/10.1257/jel.49.1.72 
Del Negro, M. and Eusepi, S. (2011). Fitting Observed Inflation Expectations. Journal of Economic Dynamics and Control, 35(12), pp. 2105-2131.

https://doi.org/10.1016/j.jedc.2011.04.005

Jacobs, J. P. A. M. and van Norden, S. (2011). Modelling Data Revisions: Measurement Error and Dynamics of 'True' Values. Journal of Econometrics, 161(2), pp. 101-109. https://doi.org/10.1016/j.jeconom.2010.04.010

Milani, F. (2011). Expectations Shocks and Learning as Drivers of the Business Cycle. Economic Journal, 121(552), pp. 379-401. https://doi.org/10.1111/j.1468-0297.2011.02422.x

Slobodyan, S. and Wouters, R. (2012a). Learning in an Estimated Medium-Scale DSGE Model. Journal of Economic Dynamics and Control, 36(1), pp. 26-46. https://doi.org/10.1016/j.jedc.2011.01.016

Slobodyan, S. and Wouters, R. (2012b). Learning in a Medium-Scale DSGE Model with Expectations Based on Small Forecasting Models. American Economic Journal: Macroeconomics, 4(2), pp. 65-101. https://doi.org/10.1257/mac.4.2.65

Smets, F. and Wouters, R. (2007). Shocks and Frictions in US Business Cycles: A Bayesian DSGE Approach. American Economic Review, 97(3), pp. 586-606. https://doi.org/10.1257/aer.97.3.586 